\title{
In search of a good nanny
}

\author{
Sophie Cook clinical reviews editor
}

The BMJ

Nannying, like medicine, is a vocation. The good nanny was everything a family could wish for: she cared for, helped, and guided her family to make their own decisions, knowing when to interfere and, crucially, when to butt out.

This week Simon Capewell and Richard Lilford debate whether, when it comes to states, nannying makes us healthier and whether information or legislation is the way to change health behaviour (doi:10.1136/bmj.i6341). Lilford explains, "There can be no autonomy if the state, rather than the individual, is the custodian of personal values." He warns, "The nanny state's impatient and sometimes self righteous zeal could do more harm than good." Capewell argues that, on the contrary, a "nanny state means ensuring a healthy environment for all" and underpins every health determinant in Ivan Maslow's hierarchy of needs, such as safety and love, to allow us to enjoy our health and fulfil our true potential.

One group lacking many fundamentals of Maslow's pyramid is homeless people, who often struggle to access healthcare. Anne Gulland describes how some successful UK projects have broken down barriers to services (doi:10.1136/bmj.i6511).
Helpful tips include drop-in clinics, more flexible appointment times, and awareness that lack of a permanent address is not a barrier to registering with a GP.

From a group that struggles to access healthcare to a group offered it in abundance: pregnant women. Karin Nelson and colleagues look at the role of electronic fetal monitoring in labour and at how an intervention that was initially introduced to reduce cerebral palsy (it has not) has subsequently been linked to increased rates of caesarean delivery and litigation (doi:10. 1136/bmj.i6405). They call for doctors, courts, and the public to recognise the lack of proof for routine electronic monitoring and remind us that technologies in healthcare can have unintended consequences.

And finally, as we approach the end of a turbulent year in the NHS Margaret McCartney tells us it's a sense of vocation that keeps it going (doi:10.1136/bmj.i6526), with doctors committed to going the extra mile. But this commitment also means that professionals can be exploited, she says, and that vocation "needs to be ballsy and capable of rebellion." Will 2017 bring the "righteous vocational fury" she is hoping for? 